\title{
Are Online Shoppers Interested in Learning about Locally Grown Fresh Produce?
}

\author{
Jean Dominique Gumirakiza ${ }^{1}$, Thomas Kingery ${ }^{1} \&$ Stephen King ${ }^{1}$ \\ ${ }^{1}$ Western Kentucky University, Bowling Green, KY, USA \\ Correspondence: Jean Dominique Gumirakiza, Western Kentucky University, 1906 College Heights Blvd \\ \#41066, Bowling Green, KY 42101-1066, USA. Tel: 270-745-5959. E-mail: dominique.gumirakiza@wku.edu
}

Received: October 18, 2017

Accepted: December 15, 2017 Online Published: February 15, 2018

doi:10.5539/jas.v10n3p42

URL: https://doi.org/10.5539/jas.v10n3p42

The research is financed by the USDA-NIFA.

\begin{abstract}
This study describes online shoppers, explains their interests in learning about market outlets for locally/regionally grown fresh produce, and analyzes their preferences for channels to receive educational information concerning local/regional fresh produce. We used a K-mean clustering algorithm together with binary and ordered Logit models to analyze data collected in 2016 from a stratified randomly selected sample of 1,205 online shoppers within the U.S. South region. We found that the probability for online shoppers to be interested in learning about market outlets for local/regional grown fresh produce is 66 percent. Results also indicate that the likelihood for the word-of-mouth to be at least preferred (preferred, very preferred, and extremely preferred) as channel to receive educational information about local fresh produce is 69 percent. The probabilities for local radio/TV stations, Internet-based, newspapers, and ads on public places to be at least preferred are 61 percent, 48 percent, 57 percent, and 66 percent respectively. Findings from this study are useful for fresh produce growers, agricultural marketers and educators, online shoppers, and further research studies.
\end{abstract}

Keywords: online shoppers, learning, local/regional fresh produce

\section{Introduction}

Online markets are increasingly becoming popular among consumers and businesses. Advantageously, online shopping offers some flexibility, convenience, and time saving for consumers. However, the online marketplace has some disadvantages. Consumers do not have the instant gratification of the purchase and the personal communication compared to those in the traditional offline shoppers. Online shopping does not allow physical examination of the product. It also does not allow the consumer to feel, touch, sample, or try a particular product before the purchase is made. Both consumers and businesses have an increasing interest in this type of market arrangement (Kotler \& Armstrong, 2012). Judith (2012) reported that the use of mobile devices, smartphones, and tablets contributes much to this trend. Neilson Company (2015) indicated optimistic view for fresh produce in the online market environment.

Previous studies like those of Abello et al. (2012), Conner et al. (2010), Megicks et al. (2012), Racine et al. (2010), Ruelas et al. (2012), Gumirakiza et al. (2014), Kraschnewski et al. (2014), Freedman et al. (2014), and Zepeda and Nei (2014) focused on explaining purchasing behaviors of consumers who attend famers' markets. Other studies like those of Meyer (2012), Curtis et al. (2015), and Woods and Troppy (2015) looked at consumers who participate in community supported agriculture (CSA) programs. Very little is known about how consumers make purchase decisions in the online market environment. This study is one of very few studies to focus on local/regional fresh produce among online shoppers. According to Martinez et al. (2010), local/regional fresh produce refers to fruits and vegetables grown in the individual's State or grown within a 400 mile-radius.

This study focuses on online shoppers. Research questions include: what are characteristics of online shoppers based on their monthly expenditures on fresh produce? Are online shoppers interested in learning about locally/regionally grown fresh produce? If so, what are preferred channels to convey educational information about markets for fresh produce to online consumers? This study sought to accomplish three specific objectives: (i) cluster the online shoppers based on their monthly expenditures on fresh produce, (ii) explain the interests that 
online shoppers have in learning about market outlets for local/regional fresh produce, and (iii) analyze preferences for information channels that online shoppers would like to receive educational information about local/regional fresh produce. The study is significant to growers and agricultural marketers because it provides an understanding online shoppers and their preferred ways to receive educational/marketing information. It is important for marketers to know the channels that consumers prefer to obtain information regarding accessibility of fresh produce in their communities/regions. Future researchers will find this analysis useful when furthering knowledge in this increasingly popular market.

\section{Literature Review}

There is a limited amount of literature about local fresh produce in the online marketplace. More specifically, consumers' knowledge for and characteristics of purchasing local/regionally grown fresh produce as well as identifying the information channels consumers prefer are undocumented. This may have to do with the fact that much of the local foods that are sold via traditional farmers' markets and other direct-to-consumer market outlets. There are some research articles related to the somewhat failed online retailing of grocery store products during the late 1990s and early 2000s, such as Morganosky and Cude (2002). The online grocery retailing of the late $20^{\text {th }}$ century may have been ahead of its time. There is a large volume of literature on local fresh foods via traditional marketing channels, such as farmers' markets. Examples include those of Wolf, Spittler, and Ahern (2005), Bond, Thilmanhy, and Bond (2009), Low and Vogel (2011), Nei and Zepede (2011).

The use of the Internet and online mobile apps is increasing. Thus, today there may be desire among customers of fresh local foods to learn more about shopping alternatives for these products via web based methods. Advertising of food products generally follows one of two basic types: branded advertising and generic advertising. According to Blisard (1999), branded advertising promotes the characteristics of a given brand of a food commodity, whereas generic advertising promotes the consumption of the general food commodity.

Although there appears to be little research on local fresh produce targeted towards online shoppers, Gallo (1999) indicated that mass media advertising by American food and alcohol industries was second only to that of the automotive industry. In 1997 food alone accounted for 10.7\% of U.S. household expenditures and $14.3 \%$ of U.S. advertising expenditures. At that time, only $2.2 \%$ of the $\$ 7.1$ billion was spent on advertising of fruits, vegetables, grains, and beans (Gallo, 1999). However, none of the $\$ 7.1$ billion of media used by the food industry was spent on online or Internet media. One might expect that the prevalence of online advertising of food and agriculture products has changed dramatically. Although these historical values are becoming dated, the general structure of food advertising dollars by product category has likely not changed dramatically. It is apparent that advertising of fresh and minimally processed foods, whether local or not, is a minimal proportion of the total advertising and promotion of U.S. food and agriculture products. Even if it is arguably believed that online shopping is a time-saver experience, information search in this environment can be daunting. Anderson (2011) showed that $69 \%$ of consumers who read reviews online have as much confidence in them as in personal recommendations and over $73 \%$ read up to 10 reviews before making the final purchase decision. The number of reviews for a product reflects the product popularity (Berger, 2011). This study contributes to the little literature currently available in this potentially valuable marketplace for local fresh produce.

\section{Methodology}

\subsection{Data collection Process}

We used survey data from consumers who shopped online at least twice in six months before they participated in this study. We consider such consumers to be "online shoppers." We collected data between March and July in 2016. Participants were randomly and proportionally (based on state's population) selected from 16 states that compose the South region of the U.S. (U.S. Census Bureau, 2016). 1205 online shoppers participated in the study. We created the surveys in the Qualtrics software. Qualtrics company is a professional provider of survey software which offers advanced and sophisticated tools suited for collecting data online. The company works with more than 20 online panel providers in order to constitute a quality and diverse pool of respondents that are suited to specific sample requirements. The software used a sophisticated digital fingerprinting technology to check every Internet Protocol address as an effort to ensure the validity and the quality of the data. With this software, we were able to accurately track, profile, and monitor individual responses. Survey questions were designed using embedded features that allow branching logic, question block presentation, randomization, and question timing. The features allowed us to mitigate some biases that could arise when participants respond to survey questions. For example, randomizing the question alternatives/options eliminated a possibility for a specific alternative being chosen frequently (or less frequently) simply because it appears the first (or last) on the list for all respondents (which happens in taking paper-based surveys). In the survey, we included questions that required participants to 
answer after they actually think. This strategy allowed us verify whether respondents were in fact paying attention to each question. The software excludes automatically those participants who answered incorrectly. The survey remained open until 1,205 responded all applicable questions.

\subsection{Model Specification}

In this analysis, we conducted a cluster analysis and used binary and ordered logistic models. First, a cluster analysis grouped the online shoppers into three categories based on their monthly expenditures on fresh produce. The analysis followed a partitioning clustering process where the K-Means algorithm minimizes the distance of each point from the center value of the group to which the point belongs. Using shopper characteristics, the algorithm initialized a set of cluster centers and assigned each observation in the dataset to the cluster with the nearest center. The process continued until the centers of the clusters stopped changing.

Second, we conducted a regression analysis using both binary and ordered logistic models. We assume that the online shoppers are rational with preferences that are complete and transitive (Mas-Colell et al., 1995). We further assume that the online shoppers seek to maximize satisfaction; which according to Train (2009) implies a random utility framework. In this framework, online shoppers will first select an option with the highest level of utility when faced with several choice alternatives. Their utility derived from the choice made is then specified as a linear function of the chooser and the specific choice attributes plus the error term (Keeling-Bond, Thilmany-McFadden, \& Bond, 2009). Therefore, the utility function is:

$$
U_{i j}=V_{i j}+\varepsilon_{i j}(i=1, \ldots \mathrm{I} \text { and } j=1, \ldots J)
$$

where, $V_{i j}$ determines the utility for $i^{\text {th }}$ individual and $j^{\text {th }}$ alternative. In Equation $(1), \varepsilon_{i j}$ is a random error that we assume to be iid (independently and identically distributed) in a manner corresponding to an extreme value $F\left(\varepsilon_{i j}\right)$ $=\exp \left\{-\exp \left(-\varepsilon_{i j}\right)\right\}$. According to Kennedy (2008), this assumption makes the logit model appropriate. In addition, this study assumes that $V_{i j}$ follows a linear-in-parameter utility functional form (Onozaka \& Thilmany-McFadden, 2011). As a result, $V_{i j}$ is illustrated by Equation (2) below:

$$
V_{i j}{ }^{*}=\beta^{\prime} X_{i j}+\mu_{i j}(i=1, \ldots \text { I and } j=1, \ldots J)
$$

In Equation (2) above, the $X_{i j}$ is a vector of characteristics of the chooser. The parameters $\beta$ are to be estimated and differ across alternatives. The $\mu_{i j}$ is the disturbance that account for unobserved factors.

In order to explain the impact that characteristics of online shoppers have on their willingness to receive information about market outlets for locally grown fruits and vegetables, we modeled this analysis according to the model that Wooldridge (2009) recommended when a response variable is binary.

$$
P(y=1 \mid X)=G\left(\beta_{0}+\beta_{1} X_{1}+\ldots+\beta_{k} X_{k}\right)=G\left(\beta_{0}+X \beta\right)
$$

In Equation (3) above, the $y$ is the response that a researcher is able to observe. The $k$ represents specific explanatory variables. The $G$ is a logistic function that strictly takes on values between 0 and 1 and its functional form is:

$$
G(z)=\frac{\exp (z)}{1+\exp (z)}
$$

There is an underlying latent variable $y^{*}$ that actually derives a logistic model and that variable is given by:

$$
y^{*}=\beta_{0}+X \beta+e, y=\left[y^{*}>0\right]
$$

In Equation (5) above, $y=\left[y^{*}>0\right]$ represents is an indicator function with 0 if the expression in brackets is not true and 1 otherwise. We assume that the $e$ is unrelated/indepandent $X$ and is distributed according to a standard logistic.

In order to explain the preferred channels that online shoppers would like to receive educational information about markets for local and/or organic fresh produce, we used an ordered logit model. Kennedy (2008) indicated that this model is appropriate for dependent variables with polychotomous responses that are ranking by nature. Respondents were presented five options and asked: Based on how you get information about shopping and about events in your community, order the following information channels you like to receive educational information about local/regional fresh produce. $1==\operatorname{most}$ preferred, $2==$ preferred, $3==$ somewhat preferred, 4 $==$ less preferred, $5==$ least preferred. The options were: (A) Websites and/or social media (Internet-based), (B) local radio/TV ads, (C) word-of-mouth, (D) newspapers, and (E) information displays on public places such as roadside signs, buses, etc. We followed the strategy that Train (2009) recommended when analyzing data with ordinal outcome. In this framework, an individual $i$ is assumed to assign a favorable number to the most 
preferred option (the one believed to be associated with the highest level of utility). In this framework, the utility function $U_{i j}$ for the individual $i$ takes the form:

$$
U_{i j}=\beta^{\prime} X_{i j}+\varepsilon_{i j}
$$

In Equation (6) above, the $X_{i j}$ represents a vector of characteristics of the respondent $i$. The $\beta$ is vector of parameters that we estimate in the model. It differs across the five alternatives. The $\varepsilon_{i j}$ represents factors that are not included in the model because we cannot observe them. It is assumed to be independently and identically distributed (iid) in a manner conforming to an extreme value $F\left(\varepsilon_{i j}\right)=\exp \left\{-\exp \left(-\varepsilon_{i j}\right)\right\}$ to appropriately justify a logistic model (Kennedy, 2008). In this model, the response $y$ is expressed as:

$$
y=\left\{\begin{array}{l}
1 \text { if } 0<V_{i j}{ }^{*} \leq \mu_{1} \\
2 \text { if } \mu_{1}<V_{i j}{ }^{*} \leq \mu_{2} \\
\cdots \\
J \text { if } \mu_{J-1}<V_{i j}^{*} \leq \mu_{J}
\end{array}\right\}
$$

In Equation (7) above, the $\mu_{\mathrm{s}}$ represent threshold parameters that we estimate along with the $\beta_{s}$. This model results in ordered log-odds. These log-odds measure the effects that a specific variable has on the possibility that a given channel will be in the highest category (most preferred) over lower category, such as preferred (2), somewhat preferred (3) and less preferred (4), and the least preferred (5). Dummy variables were included in the model. We interpret specific estimates as differences in the likelihood between $X_{i j}$ with 0 values and 1 . The indirect utility $V_{i j}{ }^{*}$ is given by:

$$
V_{i j}^{*}=\sum_{k=1}^{K} \beta_{k} X_{k i}+\varepsilon_{i}=Z_{i}+\varepsilon_{i}
$$

where, $X_{k i}$ represent explanatory variables, $\beta_{k}$ is a vector of parameters to be estimated, and is $\varepsilon_{i}$ represents other non-included factors as a random disturbance term. From Equation (8) above, we used to estimate the parameters is:

$$
Z_{i}=\sum_{k=1}^{K} \beta_{k} X_{k i}=E\left(Y_{i}^{*}\right)
$$

The likelihood that $y$ takes on a specific value is given by:

$$
\operatorname{Prob}\left(y=j / X_{k i}\right)=\frac{\exp \left(\beta_{k} X_{k i}\right)}{1+\exp \left(\beta_{k} X_{k i}\right)}
$$

We hypothesize a no (null) relationship between online shoppers' characteristics and the levels of the preferences they have for the information channels; i.e. $H_{0} \equiv \beta_{k}=0$. We alternatively hypothesize that the effects the characteristics of online shoppers have on the levels of their preferences are significantly different from zero; i.e. $H_{1} \equiv \beta_{k} \neq 0$. In this study, we included 12 explanatory variables to explain the interests that online shoppers have in learning about market outlets and their preferred channels to receive educational information. Age is variable representing actual age for each respondent with a minimum of 18 years. Female is a binary variable with one if a respondent's gender is female and zero otherwise. Married is a binary variable with one if a respondent is married and zero otherwise. "FPDiet_Concerns" is a dummy variable which represents shoppers who believe that eating regularly more fresh produce helps address dietary concerns. As for the "GovAssistance" variable, one represents respondents who participate in WIC program, food stamps, and/or senior nutrition assistance program and zero otherwise. Caucasian is a binary variable with one if a respondent is white and zero otherwise. The variable "IncomeYear2015" represents thousands of respondents' income in 2015. The "MonthlySpendFreshProduce" represents the average monthly expenditures on fresh produce. Education is a categorical variable with five categories (no high school, high school diploma, 2-year college degree, 4-year college degree, graduate degree). The "InterestedInLocalFP" is a 5-likert scale variable for the levels of interests that respondents have in local fresh produce. Lastly, the WouldBuyLocalProduceOnline is a 5-likert scale variable representing levels of possibility for shoppers to purchase fresh produce online.

This study uses a binary Logit model to explain interests that online shoppers have in learning about market outlets for locally/regionally grown fresh produce. An ordered logit model is used to explain preferences for information channels. Each of the coefficient estimates is the degree to which the log-odds will chance resulting from a unit chance in the corresponding variable. The coefficients' signs show the relationship; negative or positive. The numbers demonstrate the size of contribution of the specific regressor to the variation in the dependent variable. A positive estimate means that increasing the variable will increase the probability of having interests in learning about market outlets for locally/regionally grown fresh produce. A negative estimate indicates the opposite. The smaller the size of the estimate, the weaker the effect of the variable. This discussion 
focuses on those variables that have significant marginal effects. We interpret them as the relative elasticities with respect to a specific independent variable.

\section{Presentation and Discussion of Results}

\subsection{Cluster Analysis Results}

Based on the monthly expenditures on fresh produce, the clustering algorithm placed 73 percent of all respondents into the low-spender group, 21 percent in the moderate-spender category, and 6 percent in the high-spender cluster. Table 1 illustrates some descriptive statistics for the respondent characteristics that we included in the model.

Table 1. Clustered descriptive statistics

\begin{tabular}{llll}
\hline \multirow{2}{*}{ Variables } & $\begin{array}{l}\text { Cluster of } \\
\text { High Spenders }\end{array}$ & $\begin{array}{l}\text { Cluster of } \\
\text { Moderate Spenders }\end{array}$ & $\begin{array}{l}\text { Cluster of } \\
\text { Low Spenders }\end{array}$ \\
\hline Age & 41 & 44 & 49 \\
Female & 0.407 & 0.542 & 0.636 \\
Married & 0.661 & 0.627 & 0.541 \\
FPDiet_Concerns & 0.864 & 0.827 & 0.691 \\
Caucasian & 0.729 & 0.764 & 0.842 \\
IncomeYear2015 & $\$ 89.29$ & $\$ 80.98$ & $\$ 56.66$ \\
GovAssistance & 0.136 & 0.147 & 0.152 \\
InterestedInCSA & 0.723 & 0.68 & 0.501 \\
MonthlySpendFreshProduce & $\$ 289.94$ & $\$ 109.88$ & $\$ 25.40$ \\
Education & 3.814 & 3.56 & 3.281 \\
InterestedInLocalFP & 4.559 & 4.52 & 4.338 \\
WouldBuyLocalProduceOnline & 3.356 & 2.689 & 2.029 \\
Total & $59(=6 \%)$ & $225(=21 \%)$ & $784(=73 \%)$ \\
\hline
\end{tabular}

The largest cluster consists of low-spender online shoppers. The clustering algorithm placed 73 percent of all respondents into this group. In this cluster, the average monthly expenditure on fresh produce is $\$ 25.40$. An average low-spender is 49 years old. This cluster is the least affluent cluster with average annual income of $\$ 56,660$ in 2015. In this group, females are about 64 percent. This is the cluster with the lowest percentage of married (54 percent) online shoppers. Similarly, it contains the lowest number of respondents interested in CSA programs (50 percent).

Compared to other two clusters (high and moderate spenders), the percentage of low-spender online shoppers who believe that eating fresh produce could help address their dietary concerns is relatively less. It is estimated to be 69 percent as opposed to 83 and 86 percent for moderate and high spenders respectively. Almost 84 percent are Caucasians and 15 percent are recipients of food-related government assistance. An average low-spender online shopper barely completed 2 years of college education, is very interested in locally grown fresh produce. This shopper would probably not shop for fresh produce online.

The second largest cluster consists of moderate-spender online shoppers. There are 21 percent of all respondents into this cluster. An average moderate-spender online shopper spends roughly $\$ 110$ on fresh produce each month. This average moderate-spender is 44 years old, earned a gross income of $\$ 80.980$ in 2015 , and completed a 4-year college education. He/she is very interested in locally grown fresh produce and is neutral/unsure about buying local fresh produce online. This cluster contains 54 percent females, 63 percent married, and 76 percent Caucasians. The portion of respondents interested in CSA programs in this cluster is 68 percent. Moderate-spender online shoppers who believe that eating fresh produce could help address their dietary concerns is 83 percent.

Finally, the smallest cluster consists of high spenders. The clustering algorithm placed only 6 percent of all respondents into this group. In this cluster, the average monthly expenditure on fresh produce is $\$ 289.94$. An average respondent is this cluster is 41 years old. This suggests that the cluster includes a majority of consumers with children to feed at home; resulting in high expenditures on fresh produce. This cluster is the most affluent cluster with average annual income of $\$ 89,290$ in 2015. This cluster also contains the highest percentage (66 percent) of married online shoppers; which could be another explanation for high spending. There are nearly 41 percent females in this cluster.

We found that 86 percent of high-spender online shoppers believe that eating fresh produce could help address their dietary concerns. Almost 73 percent are Caucasian, 14 percent receive some sort of food-related assistance 
from government programs, and 72 percent are interested in community supported agriculture programs. We finally found that an average high-spender online shopper barely has a bachelor's degree, is extremely interested in locally grown fresh produce, but is neutral about shopping for fresh produce online. Overall, across these three clusters, online shoppers are very interested in locally grown fresh produce, but are not decisive about their likelihood to purchase it from online stores.

\subsection{Regression Results}

\subsubsection{Binary Logit Model Results}

Table 2 shows regression results from the binary logit model. In this model, 1 represents a respondent's interest in learning about market outlets for locally/regionally grown fresh produce and 0 otherwise. We focus only on those independent variables with significant marginal effects. Overall, these results show that consumer characteristics that have significant effects on the likelihood for online shoppers to be interested in learning about market outlets for local/regional fresh produce are: age, being females, believing that eating fresh produce helps address dietary habits, receiving any type of food-related assistance from government programs (WIC, food stamps, senior nutrition program and the like), low-income, being interested in the CSA programs, and having interests in purchasing fresh produce online.

Table 2. Binary logit model results

\begin{tabular}{|c|c|c|}
\hline Independent Variables & Coefficient Estimates & $\begin{array}{l}\text { Marginal Effects } \\
\operatorname{Prob}(y==1)=.66 \\
\operatorname{Prob}(y==0)=.34\end{array}$ \\
\hline Age & $0.01136^{*}$ & $0.00113^{*}$ \\
\hline Female & $0.3259 *$ & $0.0323 *$ \\
\hline Married & 0.2813 & 0.0279 \\
\hline FPDiet_Concerns & $0.5054 * *$ & $0.0501 * *$ \\
\hline Caucasian & -0.3092 & -0.0307 \\
\hline IncomeYear2015 & $-0.003701 * * *$ & $-0.000367 * * *$ \\
\hline GovAssistance & $0.5128 *$ & $0.0508^{*}$ \\
\hline InterestedInCSA & $2.2038 * * *$ & $0.218 * * *$ \\
\hline MonthlySpendFreshProduce & $1.462 \mathrm{e}-04$ & $1.45 \mathrm{e}-05$ \\
\hline \multicolumn{3}{|l|}{ Education } \\
\hline No High School & (base) & \\
\hline High School Diploma & -0.04797 & -0.00573 \\
\hline 2-Year College Degree & 0.2959 & 0.0311 \\
\hline 4-Year College Degree & 0.4121 & 0.0415 \\
\hline Graduate Degree or Higher & 0.2986 & 0.0314 \\
\hline \multicolumn{3}{|l|}{ InterestedInLocalFP } \\
\hline Not Interested & (base) & \\
\hline Somewhat Interested & 0.5692 & 0.125 \\
\hline Interested & $2.3407 *$ & $0.524 * *$ \\
\hline Very Interested & $3.0300 * *$ & $0.615^{* *}$ \\
\hline Extremely Interested & $3.3882 * * *$ & $0.647 * * *$ \\
\hline \multicolumn{3}{|l|}{ Would Buy Local Produce Online? } \\
\hline Definitely Not & (base) & \\
\hline Probably Not & $0.9348 * * *$ & $0.106^{* * *}$ \\
\hline Might or Might Not & $1.2861 * * *$ & $0.129 * * *$ \\
\hline Probably Yes & $0.8472 * *$ & $0.0988 * *$ \\
\hline Definitely Yes & $1.5192 * *$ & $0.141 * * *$ \\
\hline Constant & $-4.2788 * * *$ & \\
\hline \multicolumn{3}{|l|}{ Stats: } \\
\hline Observations & 1205 & \\
\hline LR $\operatorname{chi} 2(21)$ & 294.65 & \\
\hline Prob $>$ chi 2 & 0.0000 & \\
\hline Pseudo R2 & 0.2969 & \\
\hline Log likelihood & -348.96311 & \\
\hline
\end{tabular}

Note. The $* * *$ denotes significance at $1 \%, * *$ at $5 \%$, and $* * *$ at $10 \%$. 
This study found that shoppers with interests in the CSA programs are 22 percent more likely to learn about market outlets for local/regional fresh produce. Those who are interested in fresh produce are 52 percent more probable to learn about market outlets than those without any interests. Those who are very interested in fresh produce are 62 percent more likely. Those who are extremely interested are 65 percent more likely to learn about market outlets for locally/regionally grown fresh produce. We further found that online shoppers who would definitely purchase fresh produce online are 14 percent more likely to learn about market outlets for local/regional fresh produce. Marital status, ethnicity, monthly expenditures on fresh produce, and education have no significant effects on the probability of online shoppers being interested in learning about market outlets for local/regional fresh produce.

\subsubsection{Ordered Logit Model Results}

Results in Table 3 are coefficient estimates from the ordered logit model. For each of the five common information channels, we regressed levels of preferences (not preferred, somewhat preferred, preferred, very preferred, extremely preferred) against the twelve explanatory variables. Three of these variables (see bolded) are categorical.

Table 3. Coefficient estimates from the ordered logit model

\begin{tabular}{|c|c|c|c|c|c|}
\hline Independent Variables & Internet-Based & Radio and TV & Word of mouth & Newspapers & Public Places \\
\hline Age & $-0.016^{* * *}$ & 0.001 & -0.002 & $0.0197 * * *$ & -0.0005 \\
\hline Female & $0.4180 * * *$ & $-0.257 *$ & -0.066 & -0.219 & 0.149 \\
\hline Married & 0.06 & 0.080 & $0.374 * * *$ & 0.222 & 0.0388 \\
\hline FPDiet_Concerns & -0.171 & -0.206 & 0.096 & $-0.288^{*}$ & -0.100 \\
\hline Caucasian & -0.073 & -0.103 & -0.225 & 0.182 & 0.179 \\
\hline IncomeYear2015 & -0.294 & 0.243 & 0.243 & -0.0321 & -0.176 \\
\hline GovAssistance & 0.193 & -0.005 & 0.078 & -0.0609 & -0.163 \\
\hline InterestedInCSA & 0.001 & -0.002 & $0.003 * *$ & -0.00106 & $0.169^{*}$ \\
\hline MonthlySpendFreshProduce & -0.002 & 0.001 & 0.001 & 0.0001 & -0.0001 \\
\hline \multicolumn{6}{|l|}{ Education } \\
\hline No High School & (base) & & & & \\
\hline High School Diploma & 0.064 & 1.196 & 0.970 & -0.546 & $0.328 *$ \\
\hline 2-Year College Degree & -0.065 & 1.291 & 0.530 & -0.297 & $0.044 *$ \\
\hline 4-Year College Degree & $0.090^{*}$ & 1.114 & 0.373 & -0.0365 & $0.619^{*}$ \\
\hline Graduate Degree or Higher & 0.034 & 0.735 & 0.690 & -0.140 & $0.968 * *$ \\
\hline \multicolumn{6}{|l|}{ Interest In Fresh Produce } \\
\hline Not Interested & (base) & & & & \\
\hline Somewhat Interested & 0.427 & 14.23 & $0.070^{*}$ & -1.748 & 0.356 \\
\hline Interested & 0.282 & 13.54 & $0.085 * *$ & -1.962 & 0.320 \\
\hline Very Interested & 0.558 & 13.60 & $0.097 *$ & -1.720 & -0.165 \\
\hline Extremely Interested & 0.437 & 14.02 & $0.023 * *$ & -1.775 & -0.089 \\
\hline \multicolumn{6}{|l|}{ Would Buy Local Produce Online? } \\
\hline Definitely Not & (base) & & & & \\
\hline Probably Not & 0.360 & 0.107 & 0.183 & -0.201 & -0.081 \\
\hline Might or Might Not & 0.661 & -0.150 & 0.0562 & $-0.562 * * *$ & 0.071 \\
\hline Probably Yes & $0.782 * *$ & -0.105 & 0.305 & -0.308 & -0.105 \\
\hline Definitely Yes & $0.622 * *$ & 0.001 & $0.623 * *$ & -0.239 & 0.199 \\
\hline Constant cut 1 & $-0.68 * *$ & $12.97 *$ & $-14.40 *$ & $-2.23^{*}$ & $-3.41 * *$ \\
\hline Constant cut 2 & $0.14^{*}$ & $14.31 *$ & $-13.41 * *$ & $-1.34^{*}$ & $-2.08^{*}$ \\
\hline Constant cut 3 & $0.73 *$ & $15.25^{* *}$ & $-12.57 *$ & $-0.43 * *$ & $-1.10^{*}$ \\
\hline Constant cut 4 & $1.57^{*}$ & $16.30^{* *}$ & $-11.56 * *$ & $0.57^{*}$ & $0.09 *$ \\
\hline \multicolumn{6}{|l|}{ Stats: } \\
\hline Observations & 798 & 798 & 798 & 798 & 798 \\
\hline LR $\operatorname{chi} 2(21)$ & 69.77 & 34.63 & 38.20 & 62.20 & 20.71 \\
\hline Prob $>$ chi 2 & 0.0000 & 0.0310 & 0.0122 & 0.0000 & 0.4769 \\
\hline Pseudo R2 & 0.0281 & 0.0136 & 0.0151 & 0.0244 & 0.0082 \\
\hline Log likelihood & -1204.56 & -1253.28 & -1247.5 & -1243.73 & -1251.47 \\
\hline
\end{tabular}

Note. The *** denotes significance at $1 \%, * *$ at $5 \%$, and $* * *$ at $10 \%$. 
These findings indicate that age is a significant factor on the Internet-based channel of information. Women and younger online shoppers prefer Internet-based educational information. Another significant factor is that men prefer educational information via radio/television stations. We found that married online shoppers prefer the word-of-mouth as a way to receive information about market outlets for local/regional fresh produce. Newspapers are found to be the preferred channel among older individuals and among those who are considered FPDiet_Concerns. Those who are not interested in CSAs are more likely to prefer public places as a way to receive educational information regarding local fresh produce.

We included education, "interests in local fresh produce", and "would buy local produce online" in the model as categorical variables. We used no high school, not interested, and definitely not as base categories respectively. We found that levels of education do not have any significant effect on any one of the channels of information for locally grown fresh produce. Likewise, levels of interests in fresh produce do not have any significant effect on any one of the channels. On the other hand, we found significant differences among levels of commitment to buying local produce online. In comparison with those who would "definitely not", results indicate significant preferences for Internet-based channel among those respondents who might, probably, and definitely buy local produce online. Finally, we found that those who would probably not buy local produce online do not prefer receiving educational information through newspapers. Likewise, results indicate that those who would definitely buy local produce online less likely to prefer learning about market outlets via word-of-mouth channel. Table 4 show marginal effects each of the respondent' characteristics has on the likelihood of a specific information channel being preferred.

Table 4. Marginal effects from the ordered logit model

\begin{tabular}{|c|c|c|c|c|c|}
\hline Variables & Internet-Based & Radio/TV & Word-of-mouth & Newspapers & Public Places \\
\hline Age & $-0.0035^{* * *}$ & $-5.84 \mathrm{e}-05$ & 0.0002 & $0.035 * * *$ & $4.92 \mathrm{e}-05$ \\
\hline Female & $0.0913^{* * *}$ & $-0.0318^{*}$ & 0.00817 & 0.0393 & -0.0158 \\
\hline Married & -0.01513 & -0.0099 & $0.046^{* * *}$ & -0.0398 & -0.00413 \\
\hline FPDiet_Concerns & 0.03733 & 0.0254 & -0.0118 & $-0.0519^{*}$ & 0.0107 \\
\hline Caucasian & 0.01598 & 0.0127 & 0.0278 & -0.0327 & -0.0190 \\
\hline IncomeYear2015 & 0.06413 & -0.0300 & -0.0301 & 0.00577 & 0.0187 \\
\hline GovAssistance & -0.04225 & 0.000565 & -0.00960 & 0.0109 & 0.0174 \\
\hline InterestedInCSA & $-2.526 \mathrm{e}-04$ & 0.000196 & $0.0348 * *$ & 0.000190 & $0.0180 *$ \\
\hline MonthlySpendFreshProduce & $3.555 \mathrm{e}-04$ & -0.0001 & $-6.14 \mathrm{e}-05$ & $-8.51 e-05$ & $5.05 \mathrm{e}-05$ \\
\hline \multicolumn{6}{|l|}{ Education } \\
\hline \multicolumn{6}{|l|}{ No High School (base) } \\
\hline High School Diploma & -0.01400 & -0.203 & -0.134 & 0.0987 & $0.101 *$ \\
\hline 2-Year College Degree & 0.01445 & -0.213 & -0.0840 & 0.0503 & $0.0698^{*}$ \\
\hline 4-Year College Degree & $0.0194 *$ & -0.193 & -0.0619 & 0.0057 & $0.0774 *$ \\
\hline Graduate Degree or Higher & -0.0074 & -0.140 & -0.104 & 0.0226 & $0.062 * *$ \\
\hline \multicolumn{6}{|l|}{ Interest in Fresh Produce } \\
\hline \multicolumn{6}{|l|}{ Not Interested (base) } \\
\hline Somewhat Interested & -0.1000 & -0.897 & $0.0145^{*}$ & 0.181 & -0.0314 \\
\hline Interested & -0.0672 & -0.813 & $0.197 * *$ & 0.221 & -0.0286 \\
\hline Very Interested & -0.1282 & -0.822 & $0.0412 *$ & 0.176 & 0.0178 \\
\hline Extremely Interested & -0.1020 & -0.875 & $0.059 * *$ & 0.185 & 0.00935 \\
\hline \multicolumn{6}{|c|}{ Would Buy Local Produce Online? } \\
\hline \multicolumn{6}{|l|}{ Definitely Not (base) } \\
\hline Probably Not & 0.0832 & -0.0125 & 0.0218 & 0.0339 & 0.0089 \\
\hline Might or Might Not & 0.0456 & 0.0194 & 0.00636 & $-0.104 * * *$ & -0.0073 \\
\hline Probably Yes & $0.038 * * *$ & 0.0133 & 0.0379 & 0.0536 & 0.0115 \\
\hline Definitely Yes & $0.0682 * *$ & -0.0002 & $0.067 * *$ & 0.0408 & -0.0195 \\
\hline
\end{tabular}

Note. The $* * *$ denotes significance at $1 \%, * *$ at $5 \%$, and $* * *$ at $10 \%$.

The Marginal Effects from the ordered logit model above compares display different communication channels preferred for receiving educational information about market outlets for locally grown fruits and vegetables. We found that one more year of age among online shoppers decreases the likelihood to prefer internet-based 
information by 0.3 percent. Females are nine percent more likely to prefer Internet-based information. However, results indicate that females are three percent less likely to prefer radio and TV channels as ways to receive educational information about market outlets for local fresh produce. Those online shoppers with a 4-year college degree are two percent more partial to the Internet-based information than those without a high school diploma. In comparison with those who do not have any interests in buying local fresh produce online (base category), respondents who would definitely buy are seven percent more likely to favor Internet-based information. Being in the category of "probably yes" increases the probability of preferring Internet-based educational information by four percent.

Furthermore, results indicate that being married increases the probability of favoring word-of-mouth for local fresh produce by five percent. The online shoppers with interests in CSA programs are three percent more likely to consider the word-of-mouth as the preferred way to be educated about local fresh produce. It was found that those who are somewhat interested in local fresh produce are one percent more likely to prefer word-of-mouth. Online shoppers who are interested in local fresh produce are three percent more likely to favor receiving educational information through word-of-mouth channel. The next significant relative probability is for those who are very and extremely interested. Being very interested in local fresh produce leads to four percent more likely to prefer word-of-mouth while being extremely interested is associated with six percent more likely. As expected, age increases the likelihood that an individual prefers receiving educational information through newspapers. One extra year of age corresponds with a roughly four percent increase in that likelihood. Believing that fresh produce helps address dietary concerns decreases the probability of preferring information via newspaper by five percent.

The last category is public places as one of the possible channels to be educated about market outlets for local/regional fresh produce. The relative probability that those interested in the CSA programs prefer public places is two percent. We found that those who had a high school diploma are 10 percent more likely to prefer information displayed on public places. It was also found that the relative probability of online shoppers with a 2-Year college degree preferring public places is seven percent. Individuals with a 4-Year college degree are eight percent more likely to prefer public places. Those with a graduate degree or higher are six percent more likely to prefer public places. Table 5 shows predicted probabilities for each of the information channels to be not preferred, somewhat preferred, preferred, very preferred, or extremely preferred.

Table 5. Predicted probabilities for information channels

\begin{tabular}{llllll}
\hline \multirow{2}{*}{ Information Channels } & \multicolumn{5}{c}{ Probabilities } \\
\cline { 2 - 6 } & Not Preferred & Somewhat Preferred & Preferred & Very Preferred & Extremely Preferred \\
\hline Internet-based & .3223 & .1966 & .1424 & .1570 & .1816 \\
Radio/TV stations & .1441 & .2456 & .2310 & .2025 & .1767 \\
Word-of-mouth & .1446 & .1676 & .1999 & .2308 & .2570 \\
Newspapers & .2349 & .1948 & .2213 & .1843 & .1646 \\
Public places & .1210 & .2222 & .2375 & .2392 & .1801 \\
\hline
\end{tabular}

Findings indicate that the probability for Internet-based (website and social media) to be at least preferred (preferred, very preferred, and extremely preferred) as channel to receive educational information about markets for local/regional fresh produce is estimated to be 48 percent. The probability for local radio and TV stations is estimated to be 61 percent. The likelihood for the "word-of-mouth" to be at least preferred is 69 percent. The likelihood for the newspapers to be at least preferred is 57 percent. The likelihood for the ads on public places (roadside signs, buses, buildings) to be at least preferred is 66 percent. Clearly, many online shoppers indicated that the most preferred communication channel to receive information about market outlets for locally grown fresh produce is through word-of-mouth.

\section{Conclusion}

While several previous studies explained purchasing behaviors among consumers at famers' markets and CSA subscribers, this study focuses on online shoppers to explain the interests they have in learning about market outlets for the fresh produce that is locally/regionally grown. We also analyzed preferences for communication channels that online shoppers would like to receive educational information about local fresh produce. This study used survey data collected in 2016 from 1,205 online shoppers that we randomly selected within the U.S. Southern region. We used K-mean clustering algorithm, binary and ordered Logit models to analyze data. Based on the monthly expenditures on fresh produce, the clustering algorithm placed 73 percent of all respondents into the 
low-spender group, 21 percent in the moderate-spender category, and 6 percent in the high-spender cluster. Overall, across these three clusters, online shoppers are very interested in locally grown fresh produce, but are not decisive about their likelihood to purchase it from online stores.

Results from the binary logit model show that the probability for online shopper to be interested in learning about direct-to-consumer market outlets for local/regional fresh produce is 66 percent. Results from the ordered logit models indicate that the likelihood for the word-of-mouth to be at least preferred (preferred, very preferred, and extremely preferred) as channel to receive/access educational information about market outlets for local/regional fresh produce is 69 percent. The likelihood for local radio and TV stations is estimated to be 61 percent. The probability for Internet-based to be at least preferred is 48 percent. The likelihood for the newspapers to be at least preferred is 57 percent. The likelihood for the ads on public places to be at least preferred is 66 percent.

Findings from this study lead to several points of marketing suggestions. First, based on the fact that online shoppers are generally interested in learning about market outlets for local/regional fresh produce, marketers and promoters of these markets should develop educational tools and strategies suitable to this audience. Second, because the word-of-mouth is the most favored, this study suggests that growers/sellers of fresh produce need to take possible measures to reinforce produce quality and enhance customer satisfaction; which will consequently continue speaking favorably for fresh produce.

Third, our findings suggest that those selling (or planning to sell) fresh produce online should target all three clusters (low, moderate, and high spenders). They should pay more attention to the high-spender cluster. Major characteristics of shoppers in this cluster include: monthly expenditure on fresh produce averaging \$289.94, annual income averaging $\$ 89,290$, those who believe that eating fresh produce helps to address their dietary concerns, those who are interested in CSA programs, those with a 4-year college/university degree, and those shoppers with interests in locally grown fresh produce. Another suggestion is that industry professionals with plans to educate online shoppers about market outlets for local/regional fresh produce should target: females, those concerned with dietary habits, food-related assistance recipients, low-income, those interested in CSA programs, and those who buy (or would) fresh produce online. Finally, we invite future studies to join our efforts to explain consumer preferences for local/regional fresh produce among online shoppers. For example, factors that explain the likelihood of buying fresh produce online remain unknown.

\section{References}

Abello, F. J., Palma, M. A., Anderson, D. P., \& Waller, M. W. (2014). Evaluating the factors influencing the number of visits to farmers' markets. Journal of Food Products Marketing, 20, 17-35. https://doi.org/ $10.1080 / 10454446.2013 .807406$

Anderson, M. (2011). Harnessing the Power of Online Customer Reviews for Local Business Growth. Retrieved May 24, 2017, from http://searchengineland.com/harnessing-the-power-of-online-customer-reviews-forlocal-business-growth-92947

Berger, J. (2011). Different Drivers of Online and Offline Word of Mouth. Advances in Consumer Research, 39, $17-18$.

Blisard, N. (1999). Advertising and What We Eat: The Case of Dairy Products. American Eating Habits: Changes and Consequences. Agriculture Information Bulletin No. AIB-750. Washington, DC: USDA-ERS. Retrieved May 24, 2017, from https://www.ers.usda.gov/publications/pub-details/?pubid=42243

Bond, J. K., Thilmany, D., \& Bond, C. (2009). What Influences Consumer Choice of Fresh Produce Purchase Location? Journal of Agricultural and Applied Economics, 41(1), 61-74. https://doi.org/10.1017/S10740 70800002558

Conner, D., Colasanti, K., Ross, R. B., \& Smalley, S. B. (2010). Locally Grown Foods and Farmers Markets: Consumer Attitudes and Behaviors. Sustainability, 3(2), 742-756. https://doi.org/10.3390/su2030742

Curtis, R. K., Ward, R., Allen, K., \& Slocumd, S. (2013). Impacts of Community Supported Agriculture Program Participation on Consumer Food Purchases and Dietary Choice. Journal of Food Distribution Research, 44(1), $42-51$.

Freedman, D. A., Mattison-Faye, A., Alia, K., Guest, M. A., \& Hébert, J. R. (2014). Comparing Farmers' Market Revenue Trends Before and after the Implementation of a Monetary Incentive for Recipients of Food Assistance. Prev Chronic Dis, 11, E87. https://doi.org/10.5888/pcd11.130347 
Gallo, A. E. (1999). Food Advertising in the United States. In American Eating Habits: Changes and Consequences. Agriculture Information Bulletin No. AIB-750. Washington, DC: USDA-ERS. Retrieved May 24, 2017, from https://www.ers.usda.gov/publications/pub-details/?pubid=42243

Gumirakiza, J. D., Curtis, R. K., \& Bosworth, R. (2014). Who Attends Farmers' Markets and Why? Understanding Consumer and their Motivations. International Food and Agribusiness Management Review, 17(2), 65-82.

Judith, A. (2012). Tablets and Smartphones Transform the In-store Customer Experience. CRM Magazine, 16(1).

Keeling-Bond, J., Thilmany-McFadden, D., \& Bond, C. (2009). What influences consumer choice of fresh produce purchase location? Journal of Agricultural and Applied Economics, 41(1), 61-74. https://doi.org/ $10.1017 / \mathrm{S} 1074070800002558$

Kennedy, P. (2008). A Guide to Econometrics (6th ed.). Malden, Massachusetts: Blackwell Publishing.

Kotler, P., \& Armstrong, G. (2010). Principles of Marketing (13th ed.). New Jersey: Pearson Education.

Kraschnewski, J. L., George, D. R., Rovniak, L. S., Monroe, D. L., Fiordalis, E., \& Bates, E. (2014). Characterizing Customers at Medical Center Farmers' Markets. J Community Health, 39(4), 727-731. https://doi.org/10.1007/s10900-014-9818-X

Low, S. A., \& Vogel, S. (2011). Direct and Intermediated Marketing of Local Foods in the United States. Economic Research Report Number 128. Washington, DC: USDA-ERS. https://doi.org/10.2139/ssrn. 2114361

Martinez, S., Hand, M., Pra, M. D., Pollack, S., Ralston, K., Smith, T., ... Newman, C. (2010). Local food systems: Concepts, impacts, and issues (ERR 97). U.S. Department of Agriculture, Economic Research Service.

Mas-Colell, A., Whinston, M. D., \& Green, J. R. (1995). Microeconomic Theory. New York: Oxford University Press.

Megicks, P., Memery, J., \& Angell, R. J. (2012). Understanding local food shopping: Unpacking the ethical dimension. Journal of Marketing Management, 28(3-4), 264-289. https://doi.org/10.1080/0267257X.2012. 658838

Meyer, J. (2012). Community Supported Agriculture: A Strategic Analysis of the Market and a Competency-based Strategic Plan (A Thesis, Michigan State University, USA). Retrieved January 12, 2017, from http://ageconsearch.umn.edu/handle/140519

Morganosky, M. A., \& Cude, B. J. (2002). Consumer demand for online food retailing: Is it really a supply side issue? International Journal of Retail \& Distribution Management, 30(10), 451-458. https://doi.org/ $10.1108 / 09590550210445326$

Neilson Company. (2015). The future of grocery. E-commerce, digital technology, and changing shopping preferences around the world. Retrieved May 22, 2017, from http://www.nielsen.com/content/ dam/nielsenglobal/vn/docs/Reports/2015/

Nie, C., \& Zepeda, L. (2011). Lifestyle Segmentation of US food Shoppers to Examine Organic and Local Food Consumption. Appetite, 57(1), 28-37. https://doi.org/10.1016/j.appet.2011.03.012

Onozaka, Y., \& Thilmany-McFadden, D. (2011). Does local labeling complement or compete with other sustainable labels? A conjoint analysis of direct and joint values for fresh produce claims. American Journal of Agricultural Economics, 93(3), 693-706. https://doi.org/10.1093/ajae/aar005

Racine, E. F., Mumford, E. A., \& Laditka, S. B. (2013). Understanding Characteristics of Families Who Buy Local Produce. Journal of Nutrition Education and Behavior, 45(1), 30-38. https://doi.org/10.1016/j.jneb.2012. 04.011

Ruelas, V., Iverson, E., Kiekel, P., \& Peters, A. (2012). The Role of Farmers' Markets in Two Low Income, Urban Communities. J Community Health, 37(3), 554-562. https://doi.org/10.1007/s10900-011-9479-y

Train, K. E. (2009). Discrite Choice Methods with Simulation (2nd ed.). New York: Cambridge University Press. https://doi.org/10.1017/CBO9780511805271

U.S. Census Bureau. (2016). Census Regions and Divisions of the United States. Retrieved May 20, 2017, from http://www2.census.gov/geo/pdfs/maps-data/maps/reference/us_regdiv.pdf

Wolf, M. M., Spittler, A., \& Ahern, J. (2005). A Profile of Farmers' Market Consumers and the Perceived Advantages of Produce Sold at Farmers' Markets. Journal of Food Distribution Research, 36(1), 192-201. 
Woods, T. A., \& Troppy, D. (2015). CSAs and the Battle for the Local Food Dollar. Journal of Food Distribution Research, 46(2), 17-29.

Wooldridge, J. M. (2009). Introductory Econometrics: A Modern Approach (4th ed.). Mason, Iowa: South-Western Cengage Learning.

Zepeda, L., \& Nie, C. (2012). What Are the Odds of Being an Organic or Local Food Shopper? Multivariate Analysis of US Food Shopper Lifestyle Segments. Agriculture and Human Values, 29(4), 467-480. https://doi.org/10.1007/s10460-012-9364-z

\section{Copyrights}

Copyright for this article is retained by the author(s), with first publication rights granted to the journal.

This is an open-access article distributed under the terms and conditions of the Creative Commons Attribution license (http://creativecommons.org/licenses/by/4.0/). 